\title{
Modeling of greenhouse radiant heating
}

\author{
Mikhail Pavlov ${ }^{1 *}$, Sergey Lukin ${ }^{1}$, and Oleg Derevianko ${ }^{2}$ \\ ${ }^{1}$ Vologda State University Lenina Street 15, Vologda, 160000, Russia \\ ${ }^{2}$ Peter the Great St. Petersburg Polytechnic University, Polytechnicheskaya 29, Saint Petersburg, \\ 195251, Russia
}

\begin{abstract}
Commercially available greenhouses are commonly used for provision of year-round growing of agricultural crops at protected ground. In order to provide favorable conditions for plants growth these agricultural constructions should be equipped by artificial heating systems in cold seasons. This work presents an overview of basic traditional and alternative heating systems which find their applications in agriculture. Advantages of application of roof radiant heating with infrared radiation sources for greenhouses are discussed. It was discovered that now there is no appropriate mathematical model of greenhouse radiant heating, which takes into account both heat and mass exchange processes. Here we propose a mathematical model of radiant heating, which includes equation system of both heat and mass exchange processes for greenhouse, its enclosure and soil. The numerical calculations were performed for commercially available greenhouse "Farmer 7.5". We investigated the impact of external air temperature and heat exchange rate on the following greenhouse radiant heating characteristics: internal air temperature, heating system thermal power and water discharge for soil watering.
\end{abstract}

\section{Introduction}

The considerable part of northern countries and Russian northern territory are non-favorable regions for open-ground planting. This is due to specific climate conditions: long-lasting and severe winter and short, not always warm summer. In order to enhance the capabilities of plant growing and increase people supply with fresh vegetables (primarily, cucumbers and tomatoes), various systems and approaches are used, including mathematical simulation of soil under various exposures [1-4]. The ground-protected constructions are extensively used as they artificially provide necessary conditions for plant growth.

All ground-protected constructions can be divided into the following groups according to their capability of meeting the plant requirements: cold frame, greenhouse, warmed soil. In contrast to cold frames and warmed soil, greenhouses provide not only favorable conditions for plants growth, but protection of working people from unfavorable climatic factors [5].

Despite obvious advantages, growth of agricultural production in greenhouse conditions is a challenging task [6]. Garden crop quality is affected by a number of factors: temperature and humidity of the inner air; soil watering intensity, etc. At the simplest greenhouses with uncontrolled sun heating it is very difficult to create favorable conditions for plant growing.

\footnotetext{
${ }^{*}$ Corresponding author: pavlov_kaftgv@mail.ru
} 
At night time, especially in winter, there is no sufficient sun heating for plant growing, so these plants either die, or fail to produce. Equipping of greenhouses by additional heating and proper watering may result in increased vegetable production (for 2-3 times) and protection of plants from potential supercooling [7,8]. And under the current requirements of energysaving, the used heating technology should be energy-efficient [9-11].

There are various types of greenhouse heating and soil warming. The classical variants include water (steam), air, gas heating, or their combinations. Also it might be performed using electrical energy [12]. Apart from the listed above heating systems, there exist alternative variants, for example, using heat pumps $[13,14]$, or sun collectors $[15,16]$. Nowadays the systems for radiant heating are widely used in agriculture due to the following reasons [17-20]:

1) It is an artificial source for infrared (Sun) radiation;

2) Where is no need for boiler plant and associated equipment;

3) The process is automated;

4) It provides favorable conditions for various types of plants, especially for young bedding;

5) This system produces even heat over the soil surface;

6) It is possible to use carbon dioxide from combustion products of gaseous fuel (in gas infrared radiators) for plant nutrition, etc.

But we believe that greenhouse radiant heating is not yet well-studied. Namely, the following aspects are not considered at all: influence of variable ambient environment factors (for example, outdoor air temperature), constructional features and technological conditions on radiant heating characteristics. This analysis is rather difficult to perform due to the absence of adequate mathematical model for greenhouse radiant heating, which takes into account the relation between thermal and mass-exchange processes occurring in it, while the heat transfer problem is rather well studied for other technological systems [21-25]. All mathematical models presented in literature [26-29] have some disadvantages. Some of them do not take into account mass-transfer processes, some of them present only mathematical equations without numerical solutions. The others are difficult and cluttered since considering various heat fluxes (for example, from a man, while his presence in automated greenhouse is not necessary). Thus, this work presents a mathematical model of greenhouse radiant heating, which includes a system of equations for thermal and material balances of greenhouse and soil. This equation system was numerically solved for a certain commercially available greenhouse. Investigations of various factors influence on greenhouse radiant heating characteristics are presented.

\section{Materials and Methods}

Figure 1 presents the scheme of thermal and material balances of the greenhouse with radiant heating. According to Fig. 1, the radiation heat flux $Q_{\text {rad }}(\mathrm{W})$ moves from heat source 3 (and from Sun in warm season, not shown here). Then it is incident on the soil surface 1 with temperature $t_{\text {surf }}\left({ }^{\circ} \mathrm{C}\right)$. Heat flux $Q_{\mathrm{abs}}$, which is absorbed by soil 1 , is spent for convective heat exchange with inner air of the greenhouse $Q_{\text {conv }}$, radiant heat exchange with inner surface of the enclosure $Q_{\text {radiant }}$ of temperature $t_{\mathrm{enc}}$, and for water evaporation $Q_{\mathrm{evap}}$. Some portion of heat $Q_{\text {soil }}$ penetrates into the inner soil. Heat losses in the greenhouse are also related to heat transfer through enclosure $Q_{\text {enc }}$ and with air exchange in the building $Q_{\text {vent. The heat flux }} Q_{\text {refl }}$ reflected from the soil surface 1 after multiple reflections and self-irradiations is absorbed by greenhouse enclosure 2. At soil watering of a volume $G_{\text {wat }}(\mathrm{kg} / \mathrm{s})$, the liquid is absorbed by plants (by leaves and roots, not shown here) in the amount $G_{\text {abs. }}$. Water of the discharge $G_{\text {evap, }}$, which was evaporated from the soil surface 1, leaves the greenhouse in the amount of $G_{\text {vent }}$ together with exhaust air through the ventilation aperture 4 . Temperature and relative air 
humidity of the greenhouse are equal to $t_{\text {int.air }}$ and $\varphi_{\text {int.air }}, \%$, respectively. The same parameters for external air are equal to $t_{\text {ext.air }}$ and $\varphi_{\text {ext.air }}$.

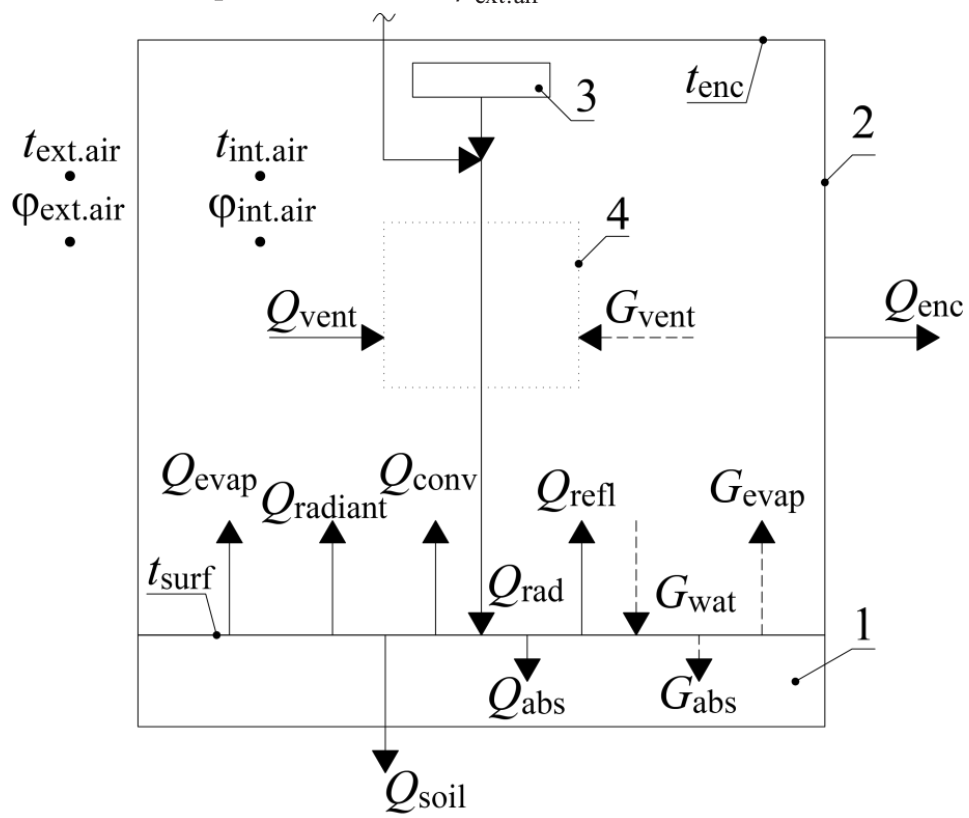

Fig. 1. The calculated scheme of thermal and material balances of the greenhouse with radiant heating: 1 - soil; 2 - enclosure; 3 - infrared radiation source; 4 - ventilation aperture (intake/exhaust)

Thermal balance equation for the greenhouse with radiant heating according to the Fig.1 is the following [17]:

$$
Q_{\mathrm{rad}}=Q_{\mathrm{enc}}+Q_{\mathrm{vent}}+Q_{\text {soil }}(\mathrm{W}),
$$

where $Q_{\text {rad }}$ is total heat flux from source 3 and Sun (at warm seasons), W; $Q_{\text {enc }}$ are heat losses through greenhouse enclosure $2, \mathrm{~W} ; Q_{\text {vent }}$ are heat losses with ventilator air, which goes out of the greenhouse through ventilation aperture $4, \mathrm{~W} ; Q_{\text {soil }}$ are heat losses into the soil, W.

Taking into consideration radiant heating specific features, heat losses $Q_{\text {enc }}$ and $Q_{\text {soil }}$ are calculated using the expressions:

$$
\begin{aligned}
& Q_{\text {enc }}=\frac{t_{\text {enc }}-t_{\text {ext.air }}}{R_{t}} F_{\text {enc }}\left(1+\beta_{\text {inf }}\right), \mathrm{W}, \\
& Q_{\text {soil }}=\left(t_{\text {surf }}-t_{\text {ext.air }}\right) \sum_{i=\mathrm{I}}^{\mathrm{IV}}\left(\frac{F_{i}}{R_{t, i}-1 / \alpha_{\text {int }}}\right), \mathrm{W},
\end{aligned}
$$

where $R_{t}=R_{\text {surf }}+\frac{1}{\alpha_{\text {int }}}$ is thermal resistance for heat transfer of enclosure $2, \mathrm{~m}^{2} \cdot \mathrm{K} / \mathrm{W} ; R_{\mathrm{enc}}$ is thermal resistance of enclosure $2, \mathrm{~m}^{2} \cdot \mathrm{K} / \mathrm{W} ; \alpha_{\text {int }}$ is heat transfer coefficient for external surface of enclosure $2,23 \mathrm{~W} /\left(\mathrm{m}^{2} \cdot \mathrm{K}\right) ; F_{\text {enc }}$ is total area of the greenhouse enclosure $2, \mathrm{~m}^{2}$; $\beta_{\text {inf }}$ is external air infiltration coefficient, for greenhouses it might be taken as $0.2 ; F_{i}$ is calculated surface of the $i$-th soil segment, $\mathrm{m}^{2} ; \quad R_{t, i}$ is thermal resistance of the $i$-th soil 
segment, $\mathrm{m}^{2} \cdot \mathrm{K} / \mathrm{W}$. For the first segment thermal resistance is equal to $R_{t, \mathrm{I}}=2.1 \mathrm{~m}^{2} \cdot \mathrm{K} / \mathrm{W}$; for the second one it is equal to $R_{t, \mathrm{II}}=4.3 \mathrm{~m}^{2} \cdot \mathrm{K} / \mathrm{W}$; for the third one it is equal to $R_{t, \text { III }}=8.6 \mathrm{~m}^{2} \cdot \mathrm{K} / \mathrm{W}$; for the fourth one it is equal to $R_{t, \mathrm{IV}}=14.2 \mathrm{~m}^{2} \cdot \mathrm{K} / \mathrm{W} ; \alpha_{\text {int }}$ is heat transfer coefficient of the internal surface of the greenhouse enclosure $2,8.7 \mathrm{~W} /\left(\mathrm{m}^{2} \cdot \mathrm{K}\right)$.

The difficulties for heat flux $Q_{\text {enc }}$ estimation according to the formula (2) is related to

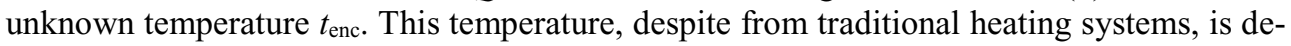
termined as a solution of heat balance equation system for the internal surface of greenhouse enclosure 2. In this system the first equation is expression (2), the second one is the following:

$$
Q_{\mathrm{enc}}=\left(1-\frac{A_{1}}{1-k_{\mathrm{abs}}}\right) Q_{\mathrm{rad}}+Q_{\mathrm{radiant}}+Q_{\mathrm{conv} 2}, \mathrm{~W},
$$

where $k_{\mathrm{abs}}=\left(1-A_{1}\right)\left(1-A_{2}\right) \frac{\varphi_{21}}{1-\varphi_{22}\left(1-A_{2}\right)}$ is the coefficient, which takes into account multiple reflections of heat radiation from the soil surface 1 and internal surface of the greenhouse enclosure 2 due to self-irradiations; $A_{1}$ and $A_{2}$ are absorption coefficients for soil surface 1 and internal surface of the greenhouse enclosure 2, respectively; $\varphi_{21}$ is radiation coefficient from the internal surface of the greenhouse enclosure 2 on the soil surface $1 ; \varphi_{22}$ is self-radiation coefficient of the enclosure 2 internal surface, $Q_{\text {radiant }}$ is the resulting heat flux obtained from radiation exchange process between soil surface 1 and internal surface of the greenhouse enclosure $2, \mathrm{~W} ; Q_{\text {conv2 }}$ is heat flux from convective heat exchange of inner air of the greenhouse and its enclosure 2 internal surface, W.

The resulting heat flux $Q_{\text {radiant }}$ obtained from radiation exchange process between soil surface 1 and internal surface of the greenhouse enclosure 2 under the condition that $t_{\text {surf }}>$ $t_{\mathrm{enc}}$ and $\varphi_{12}=1$ (the whole radiation coming from soil surface 1 falls on the inner surface of the greenhouse enclosure 2), is determined according to the formula:

$$
Q_{\text {radiant }}=c_{0} \varepsilon_{\text {soil12 }} F_{\text {surf }}\left[\left(\frac{T_{\text {surf }}}{100}\right)^{4}-\left(\frac{T_{\text {surf }}}{100}\right)^{4}\right], \mathrm{W},
$$

where $c_{0}$ is black-body radiation coefficient, $5.67 \mathrm{~W} /\left(\mathrm{m}^{2} \cdot \mathrm{K}\right) ; \varepsilon_{\text {soil12 }}$ is specific relative coefficient of heat radiation for the soil surface 1 and the internal surface of the greenhouse enclosure 2; $F_{\text {surf }}$ is surface area of soil $1, \mathrm{~m}^{2} ; T_{\text {surf }}=t_{\text {surf }}+273.15$ and $T_{\text {enc }}=t_{\text {enc }}+273.15$ are absolute temperatures of soil surface 1 and internal surface of the enclosure 2, respectively, $\mathrm{K}$.

The convective component of heat exchange between internal air and internal surface of the greenhouse enclosure 2 is calculated according to the convective heat exchange law (Newton-Richmann law):

$$
Q_{\text {conv2 }}=\alpha_{\text {int }}\left(t_{\text {int.air }}-t_{\text {enc }}\right) F_{\text {enc }}, \mathrm{W},
$$

The additional complexity of temperature $t_{\text {enc }}$ determination arises because heat flux $Q_{\text {rad }}$ enters both into equations (4) and (1). In equation (1) it is the target value.

Heat losses with gone ventilator air $Q_{\text {vent }}$ are numerically equal to heat spent for intake air heating (which incomes into the greenhouse through it ventilation aperture 4), i.e.:

$$
Q_{\mathrm{vent}}=G_{\mathrm{w}}\left(h_{\text {int.air }}-h_{\text {ext.air }}\right), \mathrm{W},
$$


where $G_{\mathrm{w}}$ is mass flow rate of the dry part of wet air, which is involved in air exchange in greenhouse, $\mathrm{kg} / \mathrm{s} ; h_{\text {int.air }}$ and $h_{\text {ext.air }}$ are specific enthalpy of internal and external wet air, $\mathrm{J} / \mathrm{kg}$.

Heat balance equations for working soil surface 1 which takes into account multiple reflections of heat radiation and self-radiations of internal surface of the greenhouse enclosure 2 is the following:

$$
\frac{A_{1} Q_{\text {rad }}}{1-k_{\text {refl }}}=Q_{\text {conv } 1}+Q_{\text {radiant }}+Q_{\text {evap }}+Q_{\text {soil }}, \mathrm{W},
$$

Where $Q_{\text {conv1 }}$ is heat flux which is generated by a convective heat exchange between soil surface 1 and surface air layer in the greenhouse (it is marked as $Q_{\text {conv }}$ in Fig. 1 ), W; $Q_{\text {evap }}$ is heat flux, which is spent for water evaporation from soil surface $1, \mathrm{~W}$.

Convective heat exchange between soil surface 1 and surface air layer in the greenhouse is governed by Newton-Richmann law:

$$
Q_{\text {conv1 }}=\alpha_{\mathrm{c}}\left(t_{\text {surf }}-t_{\text {int.air }}\right) F_{\text {surf }}, \mathrm{W},
$$

where $\alpha_{\mathrm{c}}$ is heat transfer coefficient of soil surface $1, \mathrm{~W} /\left(\mathrm{m}^{2} \cdot \mathrm{K}\right)$.

Heat flux $Q_{\text {evap }}$, which is connected with process of vaporization on the soil surface 1 , is calculated according to the equation:

$$
Q_{\text {evap }}=G_{\text {evap }} r, \mathrm{~W},
$$

Where $G_{\text {evap }}$ is water evaporation from soil surface $1, \mathrm{~kg} / \mathrm{s} ; r$ is specific heat of phase transition, $\mathrm{J} / \mathrm{kg}$.

\section{Results}

We will perform the numerical calculation of the equation system for thermal and material balances of greenhouse and soil with radiant heating. As the example we will use commercially available greenhouse "Farmer 7.5" (LLC "Volya", Moscow Region, Russia), Figure 2.

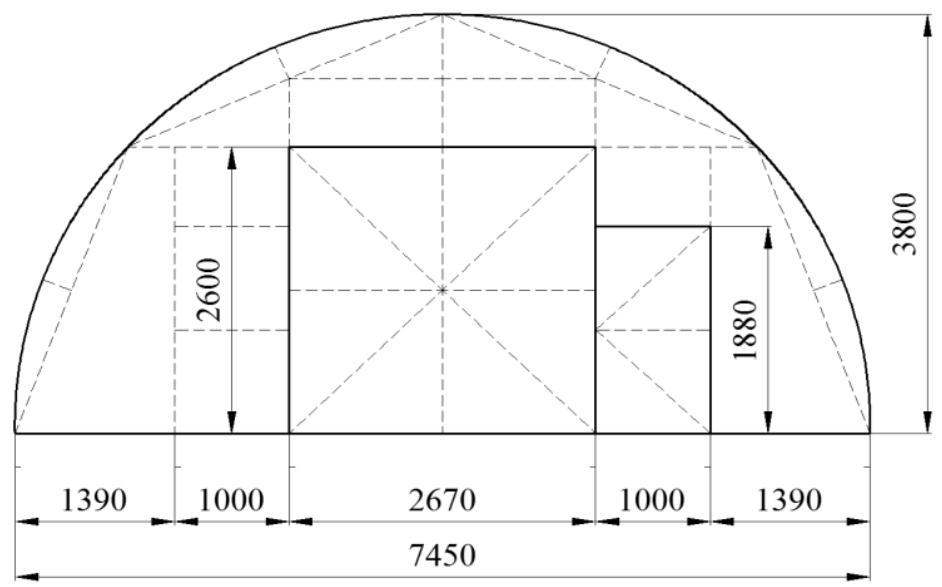

Fig. 2. Commercially available greenhouse "Farmer 7.5" (face view)

Figure 3 presents temperature curve for the internal air $t_{\text {int.air, }}{ }^{\circ} \mathrm{C}$, as a function of air exchange rate $n_{\mathrm{a}}, \mathrm{m}^{3} / \mathrm{h}$ per $1 \mathrm{~m}^{2}$, for various external air temperatures $t_{\text {extair, }}{ }^{\circ} \mathrm{C}$. 




Fig. 3. Internal air temperature tint.air as a function of air exchange rate $n$ a:

$1-$ text.air $=-30{ }^{\circ} \mathrm{C} ; 2-$ text.air $=-20{ }^{\circ} \mathrm{C} ; 3-$ text.air $=-10{ }^{\circ} \mathrm{C} ; 4-$ text.air $=0{ }^{\circ} \mathrm{C} ; 5-$ text.air $=10{ }^{\circ} \mathrm{C}$

The relation between heat flux density $q_{\mathrm{rad}}\left(\mathrm{W} / \mathrm{m}^{2}\right)$, and heat exchange rate $n_{\mathrm{a}}\left(\mathrm{m}^{3} / \mathrm{h}\right.$ per $\mathrm{m}^{2}$ ) is shown in Figure 4 . The relation between soil wetting intensity $g_{\text {wat }}$, heat exchange rate $n_{\mathrm{a}}$, and external air temperature $t_{\text {ext.air }}$, is shown in Figure 5.

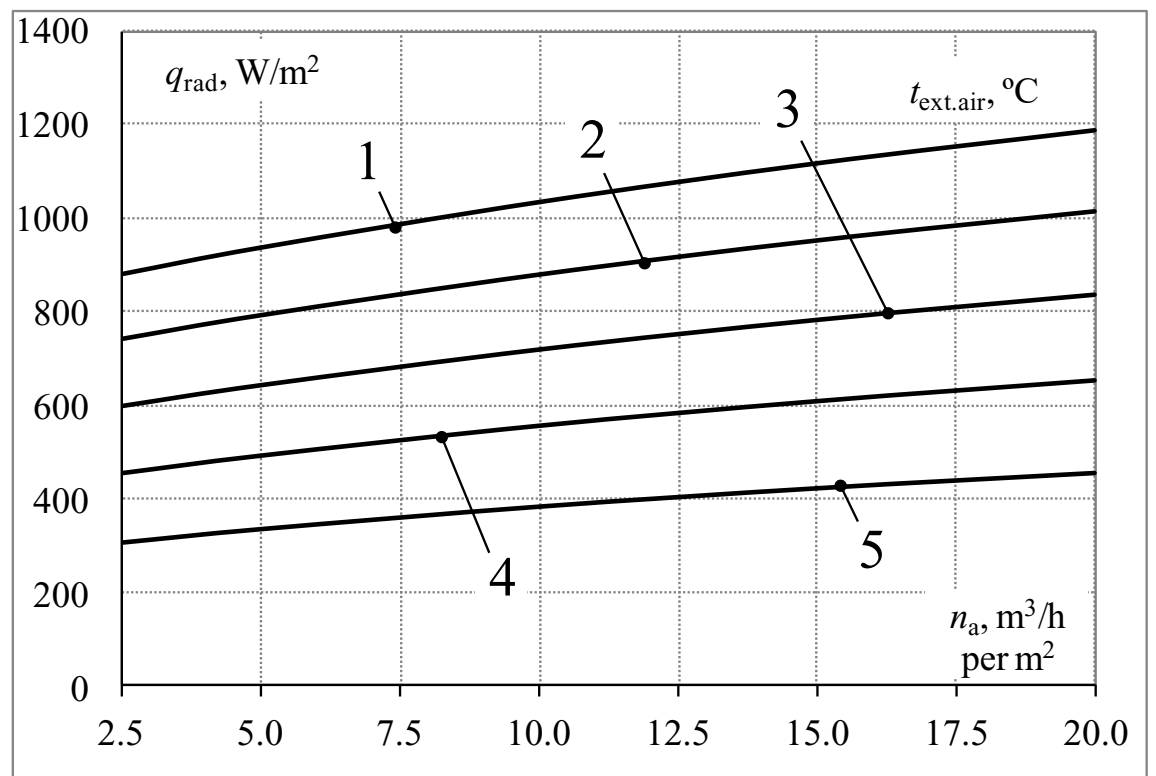

Fig. 4. Radiant heat flux density $q_{\mathrm{rad}}=q_{\mathrm{rad}}\left(n_{\mathrm{a}}\right)$ :

$1-t_{\text {ext.air }}=-30{ }^{\circ} \mathrm{C} ; 2-t_{\text {ext.air }}=-20^{\circ} \mathrm{C} ; 3-t_{\text {ext.air }}=-10{ }^{\circ} \mathrm{C} ; 4-t_{\text {ext.air }}=0{ }^{\circ} \mathrm{C} ; 5-t_{\text {ext.air }}=10{ }^{\circ} \mathrm{C}$ 


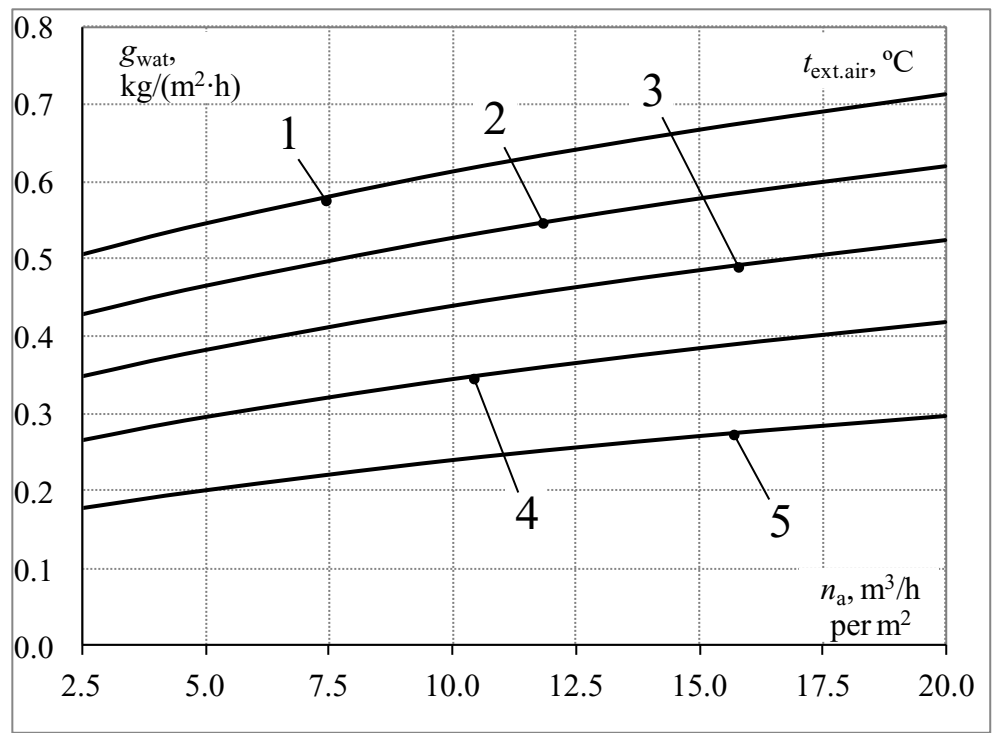

Fig. 5. Soil wetting intensity $g_{\text {wat }}=g_{\text {wat }}\left(n_{\mathrm{a}}\right)$ :

$1-t_{\text {ext.air }}=-30{ }^{\circ} \mathrm{C} ; 2-t_{\text {ext.air }}=-20^{\circ} \mathrm{C} ; 3-t_{\text {ext.air }}=-10{ }^{\circ} \mathrm{C} ; 4-t_{\text {ext.air }}=0{ }^{\circ} \mathrm{C} ; 5-t_{\text {ext.air }}=10{ }^{\circ} \mathrm{C}$

\section{Discussion}

According to the Fig.3, at air exchange rate $n_{\text {a }}$ growth, the internal air temperature $t_{\text {int.air }}$ decreases. For example, at external air temperature $t_{\text {ext.air }}=-30{ }^{\circ} \mathrm{C}$ in the range $n_{\mathrm{a}} \in[2.5 ; 20] \mathrm{m}^{3} / \mathrm{h}$ per $1 \mathrm{~m}^{2}$, it will decrease for $7.6^{\circ} \mathrm{C}$. It is due to the fact that with $n_{\mathrm{a}}$ increasing, the amount of intake air increases. Consequently, more heat is spent for its heating, and the internal air temperature $t_{\text {int.air }}$ decreases. Since the heat losses through greenhouse enclose are directly proportional to external air temperature $t_{\text {ext.air, }}$ so when it decreases, the temperature of the air in the room becomes less too.

The heat losses related to ventilation air, which is leaving the greenhouse are the first one to increase when heat exchange rate grows. So, the heat radiation power should be increased. For example, at external air temperature $t_{\text {ext.air }}=-30{ }^{\circ} \mathrm{C}$ and heat exchange rate $n_{\mathrm{a}}=2.5 \mathrm{~m}^{3} / \mathrm{h}$ per $\mathrm{m}^{2}$, the heat flux density should be equal to $q_{\mathrm{rad}}=881 \mathrm{~W} / \mathrm{m}^{2}$; at $n_{\mathrm{a}}=20.0 \mathrm{~m}^{3} / \mathrm{h}$ per $\mathrm{m}^{2}$ the heat flux density should be equal to $q_{\mathrm{rad}}=1185 \mathrm{~W} / \mathrm{m}^{2}$. As it was stated before, with external air decrease, the heat losses through enclosure increase (transmission heat losses). So, according to the greenhouse heat balance equation (1), heat radiation source power should be increased.

According to the Figure 5, with heat exchange rate $n_{\text {a }}$ growing and external air temperature $t_{\text {ext.air }}$ decreasing, water consumption for the soil wetting $g_{\text {wat }}, \mathrm{kg} /\left(\mathrm{m}^{2} \cdot \mathrm{h}\right)$ should be increased. For example, at fixed external air temperature $t_{\text {ext.air }}=-30{ }^{\circ} \mathrm{C}$, the soil wetting density in the range $n_{\mathrm{a}} \in[2.5 ; 20] \mathrm{m}^{3} / \mathrm{h}$ per $\mathrm{m}^{2}$ should be increased for about 1.5 times, from 0.506 to $0.713 \mathrm{~kg} /\left(\mathrm{m}^{2} \cdot \mathrm{h}\right)$. This is explained by the fact that with heat exchange rate growth the moisture losses with exhaust air increase. So it should be compensated be soil watering.

\section{Conclusions}

The developed mathematical model of greenhouse radiant heating allows one to determine its important characteristics, such as: the demanded total power of the heat radiation from infrared heating units and the necessary water discharge for soil wetting at preset conditions. 
The latter are external air temperature, heat exchange rate in the room, etc. The obtained plots for numerical solution of the mathematical model might be used when creating the engineering technique for radiant heating calculation of greenhouse and other agricultural facilities. This technique may be based on determination of the reference specific factors $q_{\mathrm{rad}}, \mathrm{W} / \mathrm{m}^{2}$, and $g_{\text {wat }}, \mathrm{kg} /\left(\mathrm{m}^{2} \cdot \mathrm{h}\right)$ from the obtained charts. Further, these values should be adjusted using corrective coefficients for the examined greenhouse taking into account its constructive, heat engineering, aerodynamic and other characteristics.

\section{References}

1. V. V Terleev, A.G. Topaj and W. Mirschel, Russ. Meteorol. Hydrol. 40, 278-285 (2015).

2. S. Medvedev, A. Topaj, V. Badenko, V. Terleev, V.. IFIP Advances in Information and Communication Technology, 4, 17-22 ( 2015).

3. A. Nikonorov, V. Terleev, S. Pavlov, I. Togo, Y. Volkova, T. Makarova et al., Procedia Engineering, 165, 1741-1747 (2016).

4. V. Terleev, E. Petrovskaia, A. Nikonorov, V. Badenko, Y. Volkova, S. Pavlov et al., MATEC Web of Conferences, 15, 73 (2016).

5. V.V. Klimov, Equipment of Greenhouses for Public and Private Farms (in Russian) (Energoatomizdat, Moscow, 1992).

6. A.A. Kabanov and G.V. Nikonova, Current problems of the modern science: Proceedings of the IV Local Scientific and Practical Conference, 80-82 (2015).

7. V.A. Kybis, S.V. Bakanova, A.I. Eremkin and N.A. Orlova, Urban Dev. Archit. 2, 94-98 (2014).

8. A.F. Lipatov, A.V. Spiridonova, E.V. Frolov, Proceedings of the V International Scientific and Practical Conference, 108-112(2017).

9. T.O. Zadvinskaya and A.S. Gorshkov, Adv. Mater. Res. 953-954, 1570-1577 (2014).

10. N. Vatin and O. Gamayunova, Appl. Mech. Mater. 672-674,. 550-553 (2014).

11. M. Penić, N. Vatin and V. Murgul, Appl. Mech. Mater. 680, 534-538 (2014).

12. A.N. Skanavi, Heating: Textbook for Colleges, (Stroyizdat, Moscow, 1988).

13. V.A. Kozhyhov, N.B. Miheeva and A.F. Semenov, Bull. Krasn. State Agric. Univ. 6, 127-132 (2009).

14. Y. Tong, T. Kozai, N. Nishioka and K. Ohyama, Biosyst. Eng. 106, 405-411 (2010).

15. M.I. Romanova and V.V. Sherstyukov, Eng. Bull. Don 4-2, 84 (2012).

16. L. Saravia, R. Echazú, C. Cadena, M. Condorí, C. Cabanillas, A. Iriarte et al., Renew. Energy 11, 119-128 (1997).

17. M.V. Pavlov, S.V. Lukin and K. A.A., Bull. Constr. Equip. 6,.40-42 (2017).

18. T.O. Kalinina, V.Y. Polyakova and K.V. Kichin Young Sci. 29, 81-86 (2016).

19. L. Goshka, Plumb. heating, air Cond. 3, 60-64 (2012).

20. M. Teitel, A. Shklyar, Y. Elad, V. Dikhtyar and E. Jerby, Acta Hortic., Int. Conf. British-Israeli Work. Greenh. Tech. Towar. 3rd Millenn. 1, 189-195 (2000).

21. N.D. Agafonova and I.L. Paramonova, Therm. Eng. (English Transl. Teploenerg). 8, 585-589 (2014).

22. E. Perlova, M. Platonova, A. Pankova, D. Nemova, M. Petrichenko and X. Rakova, Procedia Eng. 1, 795-802 (2015). 
23. M. Petrichenko, D. Nemova, E. Reich, S. Subbotina and F. Khayrutdinova, procedia Eng. 114 (2016).

24. 24 N. Harmati, Z. Jakšić and N. Vatin, Procedia Eng. 117, 791-799 (2015).

25. N.S. Kharkov, Journal of Physics: Conference Series, 1, 12116 (2017).

26. L.M. Dyskin and V.V. Shivanov, Bull. High. Educ. institutions. Constr. 8, 62-65 (2007).

27. A.M. Pendzhiev and D.A. Pendzhieva, Mod. Sci. issues Innov. 3, 4-18 (2017).

28. N.N. Bolotskih, Energy-saving. Energ. Energy Audit 9, 43-52 (2015).

29. A. Kavga, T. Panidis, V. Bontozoglou, S. Pantelakis, American Society of Agricultural and Biological Engineers, 52(6), 2055-2065 (2009) 